\title{
The influence of age cohort differentials on antenatal care attendance and supervised deliveries in Uganda
}

\author{
Sarah M. Wablembo ${ }^{1}$, Henry V. Doctor ${ }^{2,3}$ \\ 1. Makerere University, Department of Population Studies, Kampala, Uganda. 2. Columbia University, Mailman School of \\ Public Health, Department of Population \& Family Health, New York, USA. 3. Operations Research Advisor, PRRINN-MNCH \\ Programme, Abuja, Nigeria.
}

Correspondence: Henry V. Doctor. Address: Columbia University, Mailman School of Public Health, Department of Population \& Family Health, 60 Haven Avenue, New York, NY 10032, USA. E-mail: hvd2105@columbia.edu.

Received: December 19, 2012

Accepted: February 26, $2013 \quad$ Online Published: April 25, 2013

DOI : 10.5430/jnep.v3n11p101

URL: http://dx.doi.org/10.5430/jnep.v3n11p101

\section{Abstract}

Background: Utilization of maternal and child health services is very low in many sub Saharan African countries. In addition to the myriad of factors explaining low utilization of maternal and child services, differences in age cohorts are potential determinants of uptake of reproductive health services.

Purpose: The general aim of our study was to better understand the influence of age cohort of women on antenatal care (ANC) and delivery with skilled personnel. Specifically, we aimed at examining whether age cohort differences affect ANC attendance and supervised deliveries in Uganda.

Methods: We examine the influence of age cohort differences on ANC attendance and the likelihood of having supervised deliveries in Uganda among women $(n=5,004)$ aged 15-49 years who had given birth within the five years preceding the 2006 Uganda Demographic and Health Survey. Age cohorts consisted of young women born between 1982-1991 (15-24 years), the middle-aged women born between 1972-1981 (25-34 years), and the older women born between 1957-1971 (35-49 years).

Results: Generally, women were more likely to attend ANC than to deliver under skilled care. Specifically, older women (35-49 years), with low education, having more than one living child, the less wealthy, and rural residents were less likely than their counterparts to attend ANC and have a supervised delivery.

Conclusions: Efforts aimed at encouraging older women to deliver under skilled care need to be strengthened in order to improve maternal and child health. These efforts are critical as we progress towards the deadline for achieving Millennium Development Goals of maternal and child mortality reduction in 2015.

\section{Key words}

Antenatal care, Maternal and child health, Skilled delivery

\section{Introduction}

Antenatal care (ANC) attendance and delivery under professional care have always been associated with low maternal and child mortality ${ }^{[1-3]}$. A number of factors are associated with ANC and skilled delivery such as lack of transportation and 
$\operatorname{cost}^{[4,5]}$. Age, period, and cohort effects are usually considered as a combination because they are almost interrelated. Age effects are considered as the influences on an individual as a result of advancing or increases in age whereas period effects are the consequences of influences that vary over time. Cohort effects are the consequences of influences of being born at particular times. The effects of age and cohort differences usually influence many of the reproductive health processes and it is important even when addressing challenges, to put into consideration the effects of the two ${ }^{[6]}$.

Despite the significant and impressive economic growth in sub Saharan Africa since 2000, progress towards attainment of the Millennium Development Goals (MDGs) is still lagging behind particularly those related to reproductive health ${ }^{[7]}$. Maternal and child health challenges are largely one of the areas where sub Saharan Africa is lacking and this is due to a number of factors such as poor and inefficient health systems, social cultural factors like social positioning of women, and the influence of the male dominated society ${ }^{[4,5]}$. For example, in 24 out of 38 countries where a Demographic and Health Survey (DHS) had been conducted, over $80 \%$ of women had at least one antenatal visit during their last pregnancy ${ }^{[8]}$. However, in virtually all these countries, skilled birth attendance is significantly lower than ANC ${ }^{[9,10]}$.

In Uganda, the maternal mortality ratio in 2006 was estimated at 435 deaths per 100,000 live births which is far below reachable targets for the 2015 MDGs. Infant mortality rate was also estimated at 76 deaths per 1,000 live births ${ }^{\text {[11] }}$. One of the leading causes of maternal mortality in Uganda is lack of supervised deliveries. The 2006 Uganda DHS reports that $94 \%$ of women receive ANC from a skilled health worker but less than $43 \%$ deliver under professional supervision. The low proportions of women delivering under skilled care imply that complications such as post-partum hemorrhage, bleeding, among others, cannot be easily identified or are referred late. Other studies ${ }^{[4,5]}$ have shown that many factors account for lack of supervised deliveries and ANC attendance such as lack of transport, cost, poor health infrastructure, socio-cultural barriers, and poor attitude of health staff. Qualitative studies conducted in Ghana, Malawi, and Kenya showed that younger women tended to delay ANC attendance unintentionally because of uncertainty about the signs of pregnancy ${ }^{[12]}$. The World Health Organization (WHO) ${ }^{[13]}$ also reported that younger women were more likely to be unmarried and therefore unable or unwilling to attend ANC. Older women were more open about pregnancy and therefore more likely to initiate ANC attendance earlier than younger women. In Ghana, Kenya, and Malawi, older women were more likely to be influenced by socio cultural factors such as fear of witch craft and were not only unlikely to disclose their pregnancy but also less likely to attend ANC. Majority who attended ANC did so in order to receive a health card which assured them that health workers would not harass them during delivery ${ }^{[12,13]}$.

ANC coverage is high worldwide with 69\% of women in sub Saharan Africa attending at least one ANC visit while in Asia this proportion is lower at $54 \%$. However, the number of women who attend at least four ANC visits is lower in sub Saharan Africa than in other regions. For example, in Uganda, ANC coverage is high although the proportion of women having skilled delivery is much lower and this varies considerably with socio economic and demographic factors such as age, wealth index, and parity ${ }^{[14]}$. According to $\mathrm{WHO}^{[13]}$ there is a link between ANC attendance and assisted delivery and this can be used as a strategy to increase assisted delivery. Against this background, the aim of this study is to contribute to the existing literature by assessing the age cohort effects of women on ANC and skilled delivery because we believe that women born at different time periods experience different circumstances that shape their attitudes towards different phenomenon.

\section{Materials and methods}

\subsection{Data}

Data used in this study come from the 2006 Uganda DHS, a nationally representative cross-sectional survey conducted by the Uganda Bureau of Statistics with technical support from Macro International which provides support to developing countries to collect data on maternal and child health, family planning and fertility, among others. Macro International provides technical assistance to developing countries through MEASURE DHS, a United States Agency for International 
Development funded project. The DHS data are aimed at providing information to policy makers and planners on various issues related to socioeconomic development.

The Uganda 2006 DHS was the first to cover the entire country compared with the earlier surveys which were limited in geographical scope due to insecurity challenges in Northern Uganda. The Uganda 2006 DHS used a cluster sampling design and this was done in two stages: First the census sampling frame of 2002 was used to select 321 clusters. An additional 17 clusters were selected to allow for specific reporting for Karamoja area and the Internally Displaced camps. The second stage of sampling involved selecting households within the clusters. A total of 9,864 households were selected for interviews of which 9,099 were occupied. Of those occupied, 8,870 households were interviewed representing 97.5\% response rate. In the occupied households, 9,006 women (aged 15-49 years) were eligible for interviews. A total of 8,531 women were eligible and these were interviewed hence yielding a response rate of $94.7 \%{ }^{[11]}$.

For the purposes of this study, only women who had given birth within five years prior to the 2006 DHS were selected and this yielded a total sample of 5,004 women who were included in the study.

\subsection{Statistical analyses}

Women ( $\mathrm{n}=5,004)$ who had given birth within the five years prior to the 2006 DHS and were born within the cohort periods 1959-1971, 1972-1981, and 1982-1991 were the focus of this study. These periods correspond to the age cohorts of 15-24 years, 25-34 years, and 35-49 years, respectively. From the survey, analytical variables of interest were related to ANC and supervised delivery. Assessing period effects was important since people born during different time periods are exposed to and embrace issues related to their health differently. For instance, teenagers may find it easier to attend ANC because of fears and inexperience related to pregnancy and delivery compared with older women who may find it unnecessary to attend or to deliver under skilled care because of experience with previous deliveries. Therefore, it is pertinent even for purposes of policy planning, to take time, period, and cohort differences into consideration although not many studies have specifically done so.

Two dependent variables were employed in this study. The first, ANC, was defined as the percent of women who received ANC from a skilled health worker (a doctor/nurse/midwife or auxiliary midwife). This variable was coded as "1" when a woman had received ANC from a skilled health worker and "0" if otherwise. The second, dependent variable was "skilled delivery" coded as " 1 " if a woman had a delivery attended to by a skilled worker and " 0 " if otherwise. The independent variables were age cohorts (main independent variable) grouped into three (as defined earlier); residence (urban or rural), parity (because ANC attendance and skilled delivery is greatly influenced by parity of the woman); education level; wealth status (created by DHS from information on ownership of household possessions such as radio and car); marital status; and region of residence. It should be noted that using the wealth status variable, households were ranked into three groups: poor, middle, and rich based on their relative ranking on the household wealth status scale which was created using principal components analysis ${ }^{[11]}$. Univariate and bivariate analyses were conducted with the latter employing a cut-off value of $5 \%$ level of statistical significance for inferential conclusions. Logistic regression was used to assess the influence of age cohorts on ANC attendance and skilled delivery before and after adjusting for the other independent variables. Logistic regression was used since the outcome variables are dichotomous.

\section{Results}

\subsection{Selected demographic characteristics}

Demographic characteristics of the sample are reported in Table 1 . The youngest cohort comprised of $32.4 \%$ of the sample whereas the middle and oldest cohorts accounted for $44.8 \%$ and $22.8 \%$ of the sample, respectively. The average age for all women was 28.9 years and on average, the number of children ever born was 4.7. 
Table 1. Percentage distribution of women whose most recent birth occurred in the five years preceding the survey, by selected background characteristics, Uganda 2006 DHS

\begin{tabular}{|c|c|c|c|c|}
\hline \multirow[b]{2}{*}{ Characteristic } & \multicolumn{3}{|l|}{ Age cohort } & \multirow[b]{2}{*}{ Total } \\
\hline & $\begin{array}{l}\text { 1982-1991 } \\
\text { (Ages: 15-24 years) }\end{array}$ & $\begin{array}{l}\text { 1972-1981 } \\
\text { (Ages: } 25-34 \text { years) }\end{array}$ & $\begin{array}{l}\text { 1957-1971 } \\
\text { (Ages: } 35-49 \text { years) }\end{array}$ & \\
\hline Mean age (years) & 21.2 & 29.1 & 39.3 & 28.9 \\
\hline Mean parity & 1.9 & 4.5 & 7.8 & 4.7 \\
\hline \multicolumn{5}{|l|}{ Type of residence } \\
\hline Urban & 16.0 & 13.1 & 8.1 & 12.9 \\
\hline Rural & 84.0 & 86.9 & 91.9 & 87.1 \\
\hline \multicolumn{5}{|l|}{ Education level } \\
\hline None & 12.7 & 22.7 & 39.0 & 23.2 \\
\hline Primary & 66.8 & 61.4 & 52.6 & 61.2 \\
\hline Secondary+ & 20.5 & 15.9 & 8.4 & 15.7 \\
\hline \multicolumn{5}{|l|}{ Marital status } \\
\hline Never married & 10.6 & 1.7 & 0.8 & 4.4 \\
\hline Married* & 77.7 & 86.9 & 85.4 & 83.6 \\
\hline Widowed/Divorced/Separated ${ }^{\#}$ & 11.7 & 11.4 & 13.8 & 12.0 \\
\hline \multicolumn{5}{|l|}{ Wealth status } \\
\hline Poor & 45.7 & 43.6 & 48.9 & 46.1 \\
\hline Middle & 17.0 & 17.9 & 20.5 & 18.4 \\
\hline Rich & 37.3 & 38.5 & 30.6 & 35.5 \\
\hline \multicolumn{5}{|l|}{ Region of residence } \\
\hline Central 1 & 10.9 & 9.1 & 6.1 & 9.0 \\
\hline Central 2 & 7.6 & 9.1 & 8.2 & 8.4 \\
\hline Kampala & 9.0 & 6.9 & 3.9 & 6.9 \\
\hline East Central & 11.4 & 11.6 & 10.8 & 11.3 \\
\hline Eastern & 12.9 & 11.2 & 12.7 & 12.1 \\
\hline North & 20.2 & 20.7 & 26.1 & 21.8 \\
\hline West Nile & 7.8 & 9.3 & 9.4 & 8.8 \\
\hline Western & 11.2 & 10.6 & 11.8 & 11.1 \\
\hline South West & 9.1 & 11.6 & 11.1 & 10.7 \\
\hline \multicolumn{5}{|l|}{ ANC with skilled provider ${ }^{\dagger}$} \\
\hline Yes & 94.5 & 93.8 & 93.1 & 93.8 \\
\hline No & 5.6 & 6.2 & 6.9 & 6.2 \\
\hline \multicolumn{5}{|l|}{ Skilled attendance at birth } \\
\hline Yes & 51.5 & 46.0 & 34.9 & 44.2 \\
\hline No & 48.5 & 54.0 & 65.1 & 54.7 \\
\hline Number (\%) & 1,621 (32.4) & $2,243(44.8)$ & $1,140(22.8)$ & $5,004(100.0)$ \\
\hline
\end{tabular}

Source: Uganda 2006 Demographic and Health Survey

Notes: Differences between each characteristic (except for ANC) and age cohort were significant at $p<0.001$. Some percentages may not add up to 100 due to rounding of figures. *Includes those living together which comprised $17.7 \%$ of the women. \#Widowed represent $3.1 \%$, whereas the divorced and separated constitute $0.8 \%$ and $8.1 \%$ of the women, respectively. $†$ Includes doctor, nurse/midwife or auxiliary midwife.

According to Table 1 more women (91.9\%) in the older age cohorts were rural residents compared to $86.9 \%$ and $84.0 \%$ of the middle-aged and young cohorts, respectively. About a quarter (23.2\%) of all women had no education. Of those with no education, more (39.0\%) were aged 35-49 years than those aged $25-34$ years (22.7\%) and $15-24$ years (12.7\%). The pattern of women attaining higher education shows that the youngest cohort had more women (20.5\%) than the middle (15.9\%) and oldest cohorts (8.4\%). Thus, majority of women reported primary schooling (61.2\%).

Results in Table 1 further show that virtually all women were married (83.6\%) or had ever been married (12.0\%) at the time of the survey. The proportions married or ever married were also significantly higher across the age cohorts. Majority 
of the rich belonged to the middle age (38.5\%) and almost half (48.9\%) of the poor ones were aged 35-49 years. About one out of five women (21.8\%) were sampled from the North compared with the other regions. Average ANC attendance was as high as $93.8 \%$ for all women and it was highest among the 15-24 year olds (94.5\%) while the overall skilled birth attendance was less than half (44.2\%) for all women. Skilled birth attendance among the youth was higher (51.5\%) than the middle cohort (46.0\%) and the oldest cohort (34.9\%). One of the main findings from Table 1 is that more women attend ANC but do not deliver under skilled care.

The Pearson chi-square was also used to test the associations between the selected characteristics of women and ANC attendance as well as delivery under skilled care. Results (available upon request) show that there were statistically significant differences for all the selected characteristics and the two outcome variables $(p<0.001)$ except for age cohort and ANC ( $p=0.329$ ). These variables were then entered into the multivariate regression models assessing their influence on ANC and skilled delivery outcomes.

\subsection{Antenatal care attendance}

Table 2 presents logistic regression results of ANC attendance on age cohort and other independent variables. The analysis was conducted in three stages. Model 1 is the baseline effect of ANC on age cohort whereas Models 2 and 3 include additional variables to assess whether the effect of age cohort is still robust after the additional variables are taken into consideration. Consistent with results reported earlier in Table 1, the effect of age cohort on ANC attendance was not statistically significant since virtually all women attended ANC care. While others would eliminate inclusion of Models 2 and 3 based on the insignificant effect of age cohort in Model 1, we proceeded with Models 2 and 3 to assess any marginal differences in ANC attendance by age cohort. We found that in both models, age cohort remained insignificant. Nevertheless, we found that in Model 2, women with primary and secondary schooling were 1.65 times and 2.55 times, respectively, more likely to attend ANC than those with no schooling. Having more than one child was associated with lower odds of ANC attendance than those with one child. Being married more than doubled (Odds Ratio $(\mathrm{OR})=2.04)$ the odds of attending ANC. Controlling for region of residence, urban/rural residence, and wealth status in Model 3 did not change the magnitude and direction of the results. Women residing in East Central (OR=1.81), Eastern (OR=1.90), North $(\mathrm{OR}=2.23)$, West Nile (9.84), and Western regions $(\mathrm{OR}=2.12)$ were more likely to attend ANC than those residing in Central 1 region. Women from rich households were 1.49 times more likely to attend ANC than those coming from poor households.

\subsection{Skilled delivery care}

For the effect of the selected characteristics on utilization of skilled delivery care, we replicated (see Table 3) the analysis in Table 2. Results showed that women in the middle cohort (1972-1981) were $20 \%$ less likely to deliver with skilled personnel compared with women from the youngest cohort (1982-1991). Women born between 1957 and 1971 were 49\% less likely to have skilled assistance during delivery than the young women. Nevertheless, the effect of age cohort on utilization of skilled personnel during delivery changes in Model 2 after controlling for schooling, parity, and marital status. The results showed that the middle aged and older women were 1.49 and 1.40 times, respectively more likely to have skilled birth attendants (SBAs) than the young women. This shows that the effect of age cohort is influenced by other factors. Consistent with Table 2, we found that having some schooling was associated with a higher likelihood of having SBAs. As in Table 2, women with more children ever born were less likely to have skilled care during delivery. Model 3 which added marital status, region of residence, urban/rural residence, and wealth status did not change the results a great deal despite attenuation of the odds for schooling. Women residing in East Central were 1.80 times more likely to have skilled personnel at birth than those from Central 1 region. Residence in the North (OR=0.67), West Nile (OR=0.73), Western (OR=0.61), and South West (0.53) was associated with less likelihood of skilled delivery than residence in Central 1 region. Women from rural areas were $72 \%$ less likely to deliver with SBAs than their urban counterparts whereas women from rich households were 1.89 times more likely to deliver with SBAs than women from poor households. 
Table 2. Odds ratio (95\% CI) for receiving ANC during most recent pregnancy, Uganda 2006 DHS

\begin{tabular}{|c|c|c|c|}
\hline Characteristic & Model 1 & Model 2 & Model 3 \\
\hline \multicolumn{4}{|l|}{ Age cohort } \\
\hline 1982-1991 (r) & 1.00 & 1.00 & 1.00 \\
\hline 1972-1981 & $0.88(0.67,1.16)$ & $1.24(0.87,1.79)$ & $1.14(0.79,1.64)$ \\
\hline 1957-1971 & $0.79(0.58,1.08)$ & $1.40(0.87,2.25)$ & $1.22(0.75,1.97)$ \\
\hline \multicolumn{4}{|l|}{ Schooling } \\
\hline None (r) & & 1.00 & 1.00 \\
\hline Primary & & $1.65(1.27,2.14)$ & $\mathbf{1 . 6 0}(1.22,2.11)$ \\
\hline Secondary+ & & $2.55(1.63,4.00)$ & $2.21(1.34,3.64)$ \\
\hline \multicolumn{4}{|l|}{ Parity } \\
\hline $1(\mathrm{r})$ & & 1.00 & 1.00 \\
\hline $2-3$ & & $\mathbf{0 . 5 7}(0.36,0.90)$ & $\mathbf{0 . 6 2}(0.39,0.98)$ \\
\hline $4-5$ & & $\mathbf{0 . 4 8}(0.28,0.83)$ & $\mathbf{0 . 5 5}(0.32,0.94)$ \\
\hline $6+$ & & $\mathbf{0 . 4 3}(0.24,0.76)$ & $\mathbf{0 . 5 1}(0.28,0.91)$ \\
\hline \multicolumn{4}{|l|}{ Marital status } \\
\hline Never married (r) & & 1.00 & 1.00 \\
\hline Married ${ }^{*}$ & & $2.04(1.12,3.71)$ & $2.05(1.12,3.74)$ \\
\hline Widowed/divorced/separated ${ }^{\#}$ & & $1.74(0.90,3.39)$ & $1.73(0.89,3.37)$ \\
\hline \multicolumn{4}{|l|}{ Region of residence } \\
\hline Central 1 (r) & & & 1.00 \\
\hline Central 2 & & & $1.48(0.90,2.44)$ \\
\hline Kampala & & & $1.25(0.45,3.49)$ \\
\hline East Central & & & $\mathbf{1 . 8 1}(1.13,2.91)$ \\
\hline Eastern & & & $1.90(1.18,3.08)$ \\
\hline North & & & $2.23(1.42,3.51)$ \\
\hline West Nile & & & $\mathbf{9 . 8 4}(4.06,23.86)$ \\
\hline Western & & & $2.12(1.30,3.46)$ \\
\hline South West & & & $1.52(0.96,2.42)$ \\
\hline \multicolumn{4}{|l|}{ Type of residence } \\
\hline Urban (r) & & & 1.00 \\
\hline Rural & & & $0.47(0.22,1.03)$ \\
\hline \multicolumn{4}{|l|}{ Wealth status } \\
\hline Poor (r) & & & 1.00 \\
\hline Middle & & & $1.22(0.87,1.71)$ \\
\hline Rich & & & $1.49(1.05,2.10)$ \\
\hline$N$ & 5,003 & 5,003 & 5,003 \\
\hline Log likelihood & -1158.54 & -1140.04 & -1113.88 \\
\hline Prob $>$ chi2 & 0.329 & 0.000 & 0.000 \\
\hline
\end{tabular}

Source: Uganda 2006 Demographic and Health Survey

Notes: *Includes those living together which comprised $17.7 \%$ of the women. \#Widowed represent $3.1 \%$, whereas the divorced and separated constitute $0.8 \%$ and $8.1 \%$ of the women, respectively. "r" reference category. Bold estimates are significant at $\mathrm{p}<0.05$. 
Table 3. Odds ratios (95\% CI) for supervised delivery during most recent birth, 2006 Uganda DHS

\begin{tabular}{|c|c|c|c|}
\hline Characteristics & Model 1 & Model 2 & Model 3 \\
\hline \multicolumn{4}{|l|}{ Age cohort } \\
\hline 1982-1991 (r) & 1.00 & 1.00 & 1.00 \\
\hline 1972-1981 & $\mathbf{0 . 8 0}(0.71,0.91)$ & $1.49(1.24,1.78)$ & $1.50(1.24,1.83)$ \\
\hline $1957-1971$ & $\mathbf{0 . 5 1}(0.43,0.59)$ & $1.40(1.09,1.79)$ & $1.46(1.12,1.91)$ \\
\hline \multicolumn{4}{|l|}{ Schooling } \\
\hline None (r) & & 1.00 & 1.00 \\
\hline Primary & & $1.93(1.66,2.25)$ & $1.47(1.25,1.74)$ \\
\hline Secondary+ & & $7.83(6.27,9.79)$ & $3.30(2.56,4.25)$ \\
\hline \multicolumn{4}{|l|}{ Parity } \\
\hline $1(\mathrm{r})$ & & 1.00 & 1.00 \\
\hline $2-3$ & & $\mathbf{0 . 5 3}(0.43,0.66)$ & $\mathbf{0 . 5 3}(0.42,0.66)$ \\
\hline $4-5$ & & $\mathbf{0 . 4 1}(0.32,0.52)$ & $\mathbf{0 . 3 7}(0.28,0.48)$ \\
\hline $6+$ & & $\mathbf{0 . 3 1}(0.24,0.41)$ & $\mathbf{0 . 2 9}(0.21,0.38)$ \\
\hline \multicolumn{4}{|l|}{ Marital status } \\
\hline Never married (r) & & 1.00 & 1.00 \\
\hline Married $^{*}$ & & $0.89(0.64,1.24)$ & $1.02(0.72,1.45)$ \\
\hline Widowed/Divorced/Separated ${ }^{\#}$ & & $0.94(0.65,1.35)$ & $0.98(0.67,1.45)$ \\
\hline \multicolumn{4}{|l|}{ Region of residence } \\
\hline Central 1 (r) & & & 1.00 \\
\hline Central 2 & & & $0.96(0.72,1.28)$ \\
\hline Kampala & & & $1.50(0.88,2.52)$ \\
\hline East Central & & & $\mathbf{1 . 8 0}(1.37,2.36)$ \\
\hline Eastern & & & $0.77(0.58,1.01)$ \\
\hline North & & & $\mathbf{0 . 6 7}(0.51,0.87)$ \\
\hline West Nile & & & $\mathbf{0 . 7 3}(0.54,0.98)$ \\
\hline Western & & & $\mathbf{0 . 6 1}(0.46,0.81)$ \\
\hline South West & & & $\mathbf{0 . 5 3}(0.40,0.70)$ \\
\hline \multicolumn{4}{|l|}{ Type of residence } \\
\hline Urban (r) & & & 1.00 \\
\hline Rural & & & $\mathbf{0 . 2 8}(0.20,0.38)$ \\
\hline \multicolumn{4}{|l|}{ Wealth status } \\
\hline Poor (r) & & & 1.00 \\
\hline Middle & & & $1.15(0.96,1.39)$ \\
\hline Rich & & & $\mathbf{1 . 8 9}(1.58,2.26)$ \\
\hline$N$ & 5,003 & 5,003 & 5,003 \\
\hline Log likelihood & -3407.47 & -3124.15 & -2874.12 \\
\hline Prob $>$ chi 2 & 0.000 & 0.000 & 0.000 \\
\hline
\end{tabular}

Source: Uganda 2006 Demographic and Health Survey

Notes: *Includes those living together which comprised $17.7 \%$ of the women. \#Widowed represent $3.1 \%$, whereas the divorced and separated constitute $0.8 \%$ and $8.1 \%$ of the women, respectively. "r" reference category. Bold estimates are significant at $p<0.05$. 


\section{Discussion}

This study set out to investigate the influence of age cohort on ANC attendance and supervised deliveries among women of reproductive age who had given a birth five years prior to the 2006 Uganda DHS. Additional factors were considered in the analysis by including information on schooling, parity, marital status, region of residence, urban/rural residence, and wealth status. Understanding the influence of these factors will contribute to the existing body of literature on the challenges associated with efforts to improve maternal and child health in many sub Saharan African countries. Findings from this study revealed that age cohort is associated with having skilled birth attendance but not ANC. That ANC attendance was not associated with age cohort is not unusual considering that $94 \%$ of women attended ANC compared with 44\% who had an SBA. That more women attend ANC than having their birth attended by skilled personnel has been associated with challenges related to cost, lack of transport, attitude of health staff, and poor infrastructure ${ }^{[5,9]}$. For example, a study in Tanzania ${ }^{[9]}$ found that more than $90 \%$ of women attended ANC at least once and $62 \%$ attended ANC four times or more yet less than half received skilled delivery care at available health units. In the present study, young women were less likely to have supervised deliveries and, in general, the reported supervised deliveries in this study were lower than those reported in other sub-Saharan African countries such as Angola (55\%), Malawi (57\%), Zimbabwe (67\%), Benin (79\%), and Namibia (82\%) based on data from Measure DHS ${ }^{[15]}$. The older women who were more likely to have skilled assistance at delivery may have been those who experienced complications associated with high parity births.

The results also showed that the patterns of ANC and supervised deliveries were associated with socio-economic and geographic differentials. These findings are also consistent with studies reported elsewhere ${ }^{[16,17]}$. In this study, ANC attendance and having a supervised delivery were more likely among women with some formal schooling, those living in urban areas, the rich, women with one child only, and the married. At the regional level, there was variation in ANC attendance and supervised deliveries with the former being more common among women living in East Central, Eastern, North, West Nile, and Western regions whereas the latter was less common among women in the North, West Nile, Western, and South West regions. Specifically, the fact that rural residence was less associated with uptake of supervised deliveries concurs with a study conducted in Uganda ${ }^{[18]}$ which revealed that women in rural areas attend ANC only to obtain a registration card so that they will receive better treatment from the midwife if they have to come back for any pregnancy or labor and delivery emergencies. This indicates that many women do not perceive any additional benefits of attending ANC more frequently as well as the ultimate recommendation to delivery with a skilled attendant.

The high ANC attendance associated with low uptake of supervised deliveries calls for communication efforts aimed at men and family members on the importance of skilled delivery care. Efforts also need to be strengthened to ensure that ANC sessions are comprehensive to ensure that enough time is allocated for health education and counseling since this may address any concerns or misconceptions about skilled delivery. This is also critical based on results from a study in Tanzania ${ }^{[19]}$ which showed that only $25 \%$ of women at ANC clinics were informed of the danger signs in pregnancy and during delivery, and another $40 \%$ were informed of danger signs after delivery. Intensive counseling and health education during routine ANC visits should be considered as a great opportunity to educate women, family members, and elders about the importance of skilled delivery care for all women ${ }^{[9]}$.

As part of efforts to understand the discrepancy between high ANC attendance and low deliveries with skilled care, there is also a need to recognize the importance of strong cultural forces that lead women to avoid health facility deliveries. For example, in other parts of the world such as northern Nigeria, women prefer to deliver at home because they are considered as 'strong' women in addition to the belief that having a facility delivery is not 'necessary' ${ }^{\text {[20, } 21]}$. To reach these women there is a need to strengthen the sources of advice in the community about pregnancy, birth, and the newborn. Utilization of community mobilization strategies such as establishment of women's groups involved in savings and credit activities may provide avenues to communicate improved home care practices and health-seeking behavior to pregnant and postnatal women and their family members ${ }^{[22]}$. 
Any interventions aimed at improving maternal and child health through, among other things, encouraging facility deliveries should be targeted according the different cohorts. For example, while young women are more likely to be educated than the old women, they need to be encouraged to ensure that they value facility deliveries and act as agents of change in their interactions with older women. At the same time, older women should be targeted and ensure that they dispel any myths or concerns associated with skilled delivery care since they are often the sources of advice for young women in communities.

While the factors associated with ANC attendance and skilled delivery considered in this study are not exhaustive, they provide a synopsis of the challenges associated with efforts to improve maternal and child health by 2015, the target year for achieving the MDGs. The findings reported here are commonly encountered in many parts of sub Saharan Africa, and in other countries with similar socio-cultural characteristics as in Uganda ${ }^{[5]}$. Some of the recommendations contained in this study may have a broader relevance than the Uganda setting. Nevertheless, understanding the reality and factors influencing demand and utilization of maternal and child health services in Uganda should be pursued continuously using more rigorous research approaches such as qualitative studies and key in-depth interviews with relevant stakeholders to underpin the causes of the existing situation.

The interpretation of the findings in this study should be made with caution due to some of the limitations such as the retrospective nature of the survey which may be associated with recall bias-more pronounced for events that took place five years before the survey. In addition, the patterns of delivery care may have changed at the time of this study. However, considering that behavioral changes often take a considerable time, there is enough reason to believe that there may have been marginal increases in uptake of skilled delivery care at the time of this study ${ }^{[23]}$.

\section{Conclusions}

Women's access to skilled health personnel remains an essential component of the continuum of care for women and children. The results reported here have some implications for practice. Urgent efforts are needed in Uganda to ensure that older women in particular have supervised deliveries. We need communities to raise awareness among men, women, family members, government and non-governmental organizations to consolidate their efforts to find practical solutions to increase the number of women having skilled deliveries. Strategies such as encouraging women to form groups which can focus on investments in health through savings and credit facilities will be indispensable in ensuring that members are able to pay or defray costs associated with seeking reproductive health services. Membership in such groups is a catalyst for generating demand, increased social awareness and support for appropriate maternal and child health behavior particularly among older women. Efforts aimed at introducing emergency transport systems in communities should be explored to enable women to be taken to health facilities timely. These and other efforts are critical in ensuring that Uganda accelerates its efforts to attain the MDGs of maternal and child health.

\section{Acknowledgments}

We acknowledge the U.S. Agency for International Development, ICF Macro, and the Uganda Bureau of Statistics and other partners for supporting the collection and processing of the Uganda 2006 DHS data as well as making the data available for public use.

\section{References}

[1] UNICEF. Eastern and Southern Africa Regional Office: Maternal mortality reduction strategy. 2003

[2] World Health Organization, UNICEF. Antenatal care in developing countries. Promises, achievements and missed opportunities. An analysis of trends, levels and differentials, 1990-2001. Geneva, Switzerland, 2003.

[3] Magadi M, Madise N, Diamond I. Factors associated with unfavourable birth outcomes in Kenya. J Biosoc Sci. 2001; 33: 199225. http://dx.doi.org/10.1017/S0021932001001997

Published by Sciedu Press 
[4] Maine D. Detours and shortcuts on the road to maternal mortality reduction. Lancet. 2007; 370(9595): $1380-1382$. http://dx.doi.org/10.1016/S0140-6736(07)61580-3

[5] Gabrysch S, Campbell OMR. Still too far to walk: Literature review of the determinants of delivery service use. BMC Preg Childbirth. 2009; 9:34. http://dx.doi.org/10.1186/1471-2393-9-34

[6] Doctor HV. Intergenerational differences in antenatal care and supervised deliveries in Nigeria. Health and Place. 2011; 17: 480489. http://dx.doi.org/10.1016/j/healthplace.2010.12.003

[7] Gribble J, Haffey J. Reproductive health in sub Saharan Africa. Washington DC: Population Reference Bureau; 2008.

[8] Wang W, Alva S, Wang S, Fort A. Levels and trends in the use of maternal health services in developing countries. DHS Comparative Reports No. 26. Calverton, Maryland, USA: ICF Macro, 2011.

[9] Magoma M, Requejo J, Campbell OMR, Cousens S, Filippi V. High antenatal care coverage and low skilled attendance in a rural Tanzanian district: a case for implementing a birth plan intervention. BMC Preg Childbirth. 2010; 10: 13. http://dx.doi.org/10.1186/1471-2393-10-13.

[10] Stanton, C. Blanc AK, Croft T, Choi Y. Skilled care at birth in the developing world: progress to date and strategies for expanding coverage. J Biosoc Sci. 2007; 39(1): 109-120. PMid:16522226 http://dx.doi.org/10.1017/S0021932006001271

[11] Uganda Bureau of Statistics (UBOS), Macro International Inc. Uganda Demographic and Health Survey 2006. Calverton, Maryland, USA: UBOS and Macro International Inc; 2007.

[12] Pell C, Meñaca A, Were F, Afrah NA, Chatio S, et al. Factors Affecting Antenatal Care Attendance: Results from Qualitative Studies in Ghana, Kenya and Malawi. PLoS ONE. 2013; 8(1): e53747; http://dx.doi.org/10.1371/journal.pone.0053747

[13] World Health Organization. Antenatal care in developing countries: promises, achievements and missed opportunities: an analysis of trends, levels and differentials, 1990-2001; WHO: Geneva; 2003.

[14] Tran TK, Gottvall K, Nguyen HD, Ascher H, Petzold M, 2007: Factors associated with antenatal care adequacy in rural and urban contexts-results from two health and demographic surveillance sites in Vietnam BMC Health Services Research. 2012; 12 : 40. http://www.biomedcentral.com/1472-6963/12/40. PMid:22335834 http://dx.doi.org/10.1186/1472-6963-12-40

[15] Macro International Inc. MEASURE DHS STATcompiler. http://www.measuredhs.com, May 3, 2010.

[16] Amin R, Shah NM, Becker S. Socioeconomic factors differentiating maternal and child health-seeking behaviour in rural Bangladesh: a crosssectional analysis. Int J for Equity and Health. 2010; 9: 9. PMid:20361875 http://dx.doi.org/10.1186/1475-9276-9-9

[17] Frankenberg E, Buttenheim A, Sikoki B, Suriastini W. Do women increase their use of reproductive health care when it becomes more available? Evidence from Indonesia. Stud Fam Plann. 2009; 40: 27-38. PMid:19397183 http://dx.doi.org/10.1111/j.1728-4465.2009.00184.x

[18] Mbonye AK: Risk factors associated with maternal deaths in health units in Uganda. Afr J Reprod Health. 2001; 5(3): 4753. PMid:12471928 http://dx.doi.org/10.2307/3583322

[19] Pembe AB, Urassa DP, Carlstedt A, Lindmark G, Nystrom L, Darj E. Rural Tanzanian women's awareness of danger signs of obstetric complications. BMC Preg Childbirth. 2008; 9. http://dx.doi.org/10.1186/1471-2393-9-12

[20] Doctor HV, Findley SE, Ager A, Cometto G, Afenyadu GY, Adamu F, Green C. Using community-based research to shape the design and delivery of maternal health services in Northern Nigeria. Reprod Health Matters. 2012; 20(39): $104-112$. http://dx.doi.org/10.1016/S0968-8080(12)39615-8

[21] Adamu YM, Salihu HM. Barriers to the use of antenatal and obstetric care services in rural Kano, Nigeria. J Obstet and Gynaecol. 2002; 22(6): 600-603. PMid:12554244 http://dx.doi.org/10.1080/0144361021000020349

[22] Tripathy P, Nair N, Barnett S, Mahapatra R, Borghi J, Rath S. Effect of a participatory intervention with women's groups on birth outcomes and maternal depression in Jharkhand and Orissa, India: a cluster-randomized controlled trial. Lancet. 2010; 375: 11821192. http://dx.doi.org/10.1016/S0140-6736(09)62042-0

[23] Birungi S, Odaga J, Lochoro JP, Santini S, Owiny V, De Vivo E. The quality and use of maternal health care in Oyam District, Uganda: a baseline survey for an intervention. Health Policy and Development Journal. 2009; 7(1): 35-47. 